\section{DE MÓNADAS Y SUSTANTIVIDADES O LEIBNIZ Y ZUBIRI}

\author{
Diego Gracia \\ Universidad Complutense de Madrid \\ Fundación Xavier Zubiri \\ dgracia@fcs.es
}

Cómo citar este artículo/Citation: Gracia, D. (2016). De mónadas y sustantividades o Leibniz y Zubiri. Arbor, 192 (780): a331. doi: http://dx.doi.org/10.3989/arbor.2016.780n4007

\section{ABOUT MONADS AND SUBSTANTIVITIES OR LEIBNIZ AND ZUBIRI}

Copyright: (c) 2016 CSIC. Este es un artículo de acceso abierto distribuido bajo los términos de la licencia Creative Commons Attribution (CC BY) España 3.0.
RESUMEN: Los autores resultan tanto más difíciles de entender cuanto más originales son sus planteamientos. El contexto de lectura de las obras de un innovador no puede ser otro que el previo a la innovación, aquel en que se acuñaron los términos que por necesidad él tendrá que utilizar, bien que dotándoles de nuevo sentido. Lo normal es que este nuevo sentido pase inadvertido para el lector, que tenderá a interpretar esos términos en su sentido tradicional. Esto es por demás evidente en el caso de la filosofía de Zubiri, al que con frecuencia se le ha interpretado con categorías racionalistas completamente extrañas a su pensamiento. En este artículo se intenta aclarar ese punto, confrontando la razón pura leibniziana con la inteligencia impura o sentiente de Zubiri. Son dos modos distintos de entender el pensamiento y la realidad, que generan a su vez dos teorías filosóficas divergentes.

PALABRAS CLAVE: Leibniz; Zubiri; monadología; sustantividad; razón pura; inteligencia sentiente.
ABSTRACT: The risk of understanding authors incorrectly is proportional to their innovative nature. The context of reading and understanding innovative texts cannot be other than the traditional context previous to the innovation, in which the technical language of the discipline was coined. This language is also used by the innovator, filling the old words with new meanings. Consequently, the most natural way to understand innovative texts is to interpret them in the framework of the traditional received categories, losing all of their originality. This is apparent in the case of Zubiri's philosophy, which has been frequently interpreted according to the categories common to the rationalistic tradition of Western philosophy. This article attempts to clarify this point, comparing the pure reason of Leibniz with the sentient or impure intelligence of Zubiri. These are two different ways of understanding thought and reality and, therefore, philosophy.

KEYWORDS: Leibniz; Zubiri; monadology; sustantivity; pure reason; sentient intelligence. 


\section{LEIBNIZ Y ZUBIRI}

Hoy sabemos que Zubiri concentró su labor docente durante los años de la Segunda república en el curso de "Introducción a la Filosofía", en el que organizaba la historia de la filosofía en dos horizontes, el horizonte griego de la movilidad y el horizonte cristiano de la creación. Uno de los autores que Zubiri analizó en el interior de este segundo horizonte fue Leibniz. De hecho, en el curso académico 1931-32 (Marías, 1960, p. 465), Zubiri comentó en una de sus lecciones, que por Marías sabemos fue la segunda, la idea de reflexividad en los parágrafos 29 y 30 de la Monadología de Leibniz (Marías, 1960, p. 466). No es que hiciera un seminario especial sobre la Monadología, pero sí que debió dedicar algún tiempo, al menos una clase, a la filosofía de Leibniz, apelando para exponerla a la idea de reflexividad, sin duda por el papel nuclear que desempeña en su pensamiento (Zubiri, 2007, p. 468; cf. pp. 469-475). Marías cuenta que este fue su bautismo de inmersión en la filosofía (Marías, 1960, pp. 465-466).

Fue al curso siguiente, 1932-1933, cuando Zubiri dedicó tres lecciones enteras a Leibniz, cuyo contenido se ha reconstruido a partir de los apuntes de Luis Felipe Vivanco (Zubiri, 2010, pp. 277-290). En ellas comentó el Discurso de metafísica. Marías se ha referido a ello en el artículo de 1998 "El joven Zubiri" (Marías, 3 de diciembre de 1998, p. 3). En él parece claro que Marías comete dos errores. Primero, no se trataba de la Monadología sino del Discurso de metafísica. La confusión parece deberse a que mezcla el recuerdo de este curso con el del anterior, en el que, efectivamente, comentó la Monadología. Y segundo, que ya no tenía diecisiete años sino dieciocho.

Los párrafos de la Monadología que analizó Zubiri en el primer curso, fueron el 29 y el 30 (Leibniz, 2003, pp. 697-698). En ellos creyó encontrar Zubiri el núcleo del pensamiento leibniziano. El objeto de la metafísica es el conocimiento de las verdades necesarias y eternas. Estas las encuentra el ser humano en su interior, en las verdades de pura razón, que la mente descubre de modo muy similar a como descubre los teoremas matemáticos. De hecho, así es como están necesariamente las verdades en Dios, de tal modo que el filósofo no hace otra cosa que acceder a la mente divina. Dios es sabio, ve todo bajo forma de verdades necesarias y eternas, y el filósofo, que quiere aproximarse a Dios, tiene que hacer esto mismo desde la mente humana. En este punto Leibniz se muestra como un redomado intelectualista o racionalista, opuesto a las tesis voluntaristas que en la Edad Media defendieron los teólogos de la escuela franciscana, en especial Escoto y Ockam. La tesis de Leibniz, tan diametralmente opuesta al nominalismo, es que las verdades de razón son absolutas y se le imponen al propio Dios (Leibniz, 2003, p. 247).

Zubiri dedicó las lecciones del curso siguiente a comentar el Discurso de metafísica, dado que es en ese texto donde Leibniz expone de modo más claro su teoría. El Discurso de metafísica comienza planteándose los atributos inherentes a la idea de Dios, entre los que destaca la "perfección" y que "todo lo hace de la manera más deseable" (Leibniz, 2003, p. 323). Inmediatamente arremete contra los nominalistas, es decir, "contra los que sostienen que no hay bondad en las obras de Dios o bien que las reglas de la bondad y de la belleza son arbitrarias" (Leibniz, 2003, p. 324). Esto sería aceptar en Dios lo que llama un "poder despótico" (Leibniz, 2003, p. 325), ya que no habría "por qué alabarlo por lo que ha hecho si fuera igualmente loable haciendo todo lo contrario" (Leibniz, 2003, p. 325). De ahí que considere "absolutamente extraña" la idea de los nominalistas de que "las verdades eternas de la metafísica y de la geometría y por consiguiente también las reglas de la bondad, de la justicia y de la perfección sólo son efectos de la voluntad de Dios" (Leibniz, 2003, p. 325). Leibniz no puede aceptar esto, porque considera que "obrar con menos perfección de lo posible es obrar imperfectamente" (Leibniz, 2003, p. 326), algo inconcebible en el caso de Dios. Obrar lo más perfecto, añade, no limita un ápice la libertad divina, "como si obrar con perfección según la razón soberana no fuera la más elevada libertad" (Leibniz, 2003, p. 327). Por tanto, "Dios obra siempre del modo más perfecto y más deseable que se pueda" (Leibniz, 2003, p. 327). La mente humana no puede conocer las razones por las que Dios ha actuado al elegir el orden del universo, pero "el que obra perfectamente es semejante a un geómetra excelente" (Leibniz, 2003, p. 328), a un "buen arquitecto", a un "buen padre de familia", a un "diestro ingeniero" y a un "autor sabio", y así es como Dios ha tenido que crear el orden del universo.

Pero las acciones, tanto en el caso de Dios como en el de las criaturas, "pertenecen propiamente a las sustancias individuales (actiones sunt suppositorum)" (Leibniz, 2003, p. 332). De ahí la necesidad de "explicar en qué consiste la noción de una sustancia individual" (Leibniz, 2003, p. 332). Leibniz lo hace dando una definición lógica de sustancia: "cuando se atribuyen numerosos predicados a un mismo sujeto y este sujeto no es atribuido a ningún otro se lo llama sus- 
tancia individual" (Leibniz, 2003, p. 332). Así definida, es obvio que "cada sustancia singular expresa el universo entero a su manera, y que en su noción están comprendidos todos sus acontecimientos, todas las circunstancias y todo el curso de las cosas exteriores" (Leibniz, 2003, p. 333). Y añade: "Toda sustancia es como un mundo entero y un espejo de Dios o bien de todo el universo al cual cada una expresa a su manera" (Leibniz, 2003, p. 334). "Toda sustancia lleva en cierto modo la señal de la sabiduría infinita y de la omnipotencia de Dios y la imita hasta donde puede" (Leibniz, 2003, p. 334). Está claro que la sustancia así entendida no es lo que percibimos, ni lo que aprehendemos, sino un concepto lógico-metafísico, una entidad imposible de representar imaginativamente, porque su mayor parecido no se encuentra en las cosas creadas sino en Dios. A esto es a lo que acabará llamando "mónada", y tal es la razón de que resulte siempre tan difícil imaginarse una mónada. No es un dato de experiencia, como tampoco lo es la sustancia primera aristotélica, sino un concepto estrictamente lógico (Leibniz, 2003, p. 338). Esto hace que las sustancias particulares sean "como un mundo aparte, independiente de todo excepto de Dios" (Leibniz, 2003, p. 342), de modo que "una sustancia particular no actúa jamás sobre otra sustancia particular, ni tampoco la padece" (Leibniz, 2003, p. 343). "La virtud de una sustancia particular es expresar apropiadamente la gloria de Dios" (Leibniz, 2003, p. 344).

$\mathrm{Ni}$ que decir tiene que en este nivel de lo que Leibniz llama, como Platón, "ideas”, la percepción no juega papel alguno, y menos relevante (Leibniz, 2003, p. 361). "Nada se nos podría enseñar cuya idea no estuviera ya en el espíritu" (Leibniz, 2003, p. 361). Los sentidos externos son estas "advertencias", que nos dan "nociones" (Leibniz, 2003, p. 361), pero "lo que poseo de mí y de mis pensamientos y, por consiguiente, del ser, de la sustancia, de la acción, de la identidad y de muchas otras entidades, proceden de una experiencia interna" (Leibniz, 2003, p. 363). De lo que se deduce que "las percepciones de nuestros sentidos, incluso cuando son claras, deben necesariamente encerrar algún sentimiento confuso" (Leibniz, 2003, p. 372; Leibniz, 1992, p. 101). Las "percepciones" son, para Leibniz, "confusas", y no constituyen camino adecuado para la captación de las verdades necesarias. No en vano de las percepciones gozan también los animales.

Leibniz define la verdad como "una afirmación cuyo predicado está incluido en el sujeto". (Leibniz, 2003, p. 379) Así es como Dios ve las cosas. Esta inclusión del predicado en el sujeto puede ser necesaria "con necesidad metafísica o geométrica" (Leibniz, 2003, p. 380), y entonces tenemos las "verdades necesarias", y cuando la necesidad no es de ese tipo sino fáctica, hablamos de "verdades contingentes". Entre unas y otras hay la misma distinción que entre las "esencias" y las "existencias" (Leibniz, 2003, p. 381).

Hasta aquí la exposición del pensamiento de Leibniz, siguiendo sobre todo su Discurso de metafísica. Por el índice del escrito Sobre el problema de la filosofía, de 1933, sabemos que entonces Zubiri ya no se situaba ahí, sino en lo que llama "El nuevo horizonte del filosofar: la temporalidad" (Zubiri, 2002, p. xiii). Lejos de entender la metafísica como ontoteología, él quiso hacer una metafísica mundana y tempórea, lo que le situaba ya entonces a mil leguas de Leibniz.

\section{ZUBIRI Y LEIBNIZ, O LA CRÍTICA ZUBIRIANA DE LEIBNIZ}

Si de los cursos orales anteriores a la Guerra Civil pasamos a la obra madura, dos son las exposiciones que nos quedan de la filosofía de Leibniz: una, la lección que le dedicó en el curso Los problemas fundamentales de la metafísica occidental, del año 1969. Y la otra, la exposición que de Leibniz hizo en Sobre la esencia, en el capítulo titulado "La esencia como concepto objetivo".

En Los problemas fundamentales de la metafísica occidental, Zubiri toma como punto de partida de Leibniz el orden de los posibles, ya que las cosas reales no pueden consistir en otra cosa que en la realización de los posibles. Por otra parte, sólo los posibles no contradictorios entre sí pueden hacerse reales. De ahí la importancia del principio de contradicción y del principio de razón suficiente. Este último significa, dice Zubiri, no que toda realidad haya de tener su razón de ser, sino algo aún más grave, a saber, "que lo posible, en tanto que posible -la esencia, en tanto que esencia-, está desde sí misma determinada a tener una cierta forma de existencia" (Zubiri, 1994, p. 166). Pero sucede que no todas esas formas de existencia son compatibles ni pueden existir de hecho, aunque todas tengan apetito o conato por la existencia. Y sucede también que, entre las infinitas combinaciones posibles de existencia, unas son más compatibles o perfectas que otras. Pues bien, el orden real, el orden de lo existente, es el que realiza en mayor medida los posibles sin contradicción, de donde se deduce que este mundo es el mejor de los posibles. Y las esencias así existentes son las que Leibniz denomina "mónadas", unidades o puntos metafísicos, trascendentales. La mónada es la unidad de notas de una esencia posible que se hace realidad. Contiene, obviamente, el 
mejor y mayor número de notas posibles constitutivas de su esencia, y también el mejor y mayor número de notas posibles compatibles con todas las otras mónadas. Toda mónada es perfecta en su línea, de tal modo que si bien es activa, internamente activa, no actúa sobre las demás siguiendo las leyes mecánicas, y por tanto según el orden de las causas eficientes, porque eso significaría que no es perfecta en su línea, lo cual resulta imposible. La relación con las otras mónadas no se rige por la causalidad eficiente sino por la causa final, lo que da como resultado la armonía preestablecida que es preciso postular en el mejor mundo posible. Esto hace que cada mónada sea, en el fondo, una síntesis y espejo del universo todo, o como dice Leibniz, una representación del universo desde un punto de vista (Leibniz, 2003, p. 704 y pp. 333-334).

Leibniz es la culminación de un tema que ha rodado desde los primeros días de la filosofía, a saber, el de la unidad de lo real y sus características, es decir, el de la "sustancia". La sustancia es la unidad de realidad, o la unidad real. Leibniz da de la sustancia una definición lógica, pero acto seguido afirma que ella exige desde sí misma la existencia. De hecho, hay un escrito de Leibniz, del año 1677, en el que afirma que la propia "definición real de existencia" exige "que exista lo que es máximamente perfecto de entre aquellas cosas que por lo demás podrían existir, es decir, lo que envuelve más esencia. De tal modo que la naturaleza de su posibilidad o esencia consiste en exigir su existencia. Si no fuera así, no podría darse razón de la existencia de las cosas" (Leibniz, 2003, p. 178). En el fondo, toda la obra de Leibniz es una especie de inmenso argumento ontológico.

De la sustancia se ha venido diciendo, al menos desde Aristóteles, que está constituida por diferentes notas, y que la "esencia" es el conjunto de notas inherentes o imprescindibles que la constituyen, a diferencia de otras notas que tiene pero que no la constituyen, y que por eso se llaman accidentales. La unidad de realidad, es decir, la sustancia, aparece cuando se constituye esa unidad de notas. Esta es la tesis clásica. En Leibniz esto se expresa del modo más abstracto posible, como corresponde a un gran matemático. Un conjunto de notas articulado y coherente constituye un ente "posible", que tiende a la existencia, pero que sólo puede realizarse y constituirse en "sustancia real", cuando ese conjunto es el óptimo en el orden de su coherencia interna y en el de su coherencia externa, es decir, en relación a todas las demás esencias posibles. La mónada es la sustancia más perfecta posible en orden a la existencia, y por tanto la que implica un máximo de realidad.
De lo dicho se deduce que en el sistema de Leibniz la sensibilidad no puede jugar un papel importante en la determinación de lo que es la realidad esencial o sustancialmente. De ahí que diga que la sensibilidad es simplemente intelección confusa. Zubiri destaca esto con un cierto énfasis en su exposición: "Leibniz, de un plumazo bien característico de su modo de pensar, dirá que la sensibilidad es pura y simplemente intelección confusa. Es esta una afirmación tremenda, que en su momento habrá que discutir, pero en la que ahora no entramos" (Zubiri, 1992, p. 157). Esa discusión con el concepto de sustancia y esencia en Leibniz es la que Zubiri lleva a cabo en las páginas de Sobre la esencia (Zubiri, 1985, pp. 59-73).

Leibniz piensa que para llegar a esas verdades necesarias hay que prescindir de la sensibilidad, que no puede más que confundirnos. El orden trascendental de la metafísica sólo puede alcanzarse mediante la pura razón, como en las matemáticas, de modo que sólo se halla constituido por verdades de razón. Es puro pensamiento analítico. En esto se diferencia de toda la metafísica anterior, para la que la teoría de la sustancia partía de las cosas en tanto que percibidas, si bien echando mano de una facultad, el noûs, capaz de penetrar la sobrehaz de las cosas sensibles y acceder a lo profundo y esencial. De hecho, en la filosofía griega parece claro que de la ousía o sustancia primera hay una aprehensión que es inmediata, directa, intuitiva. La sustancia se nos presenta en tanto que tal. Lo que luego tendrá carácter más discursivo será la identificación de sus caracteres, y por tanto de lo que dio en llamarse sustancia segunda.

De esto cabe concluir que la gran diferencia entre la sustancia aristotélica y la sustancia leibniziana está en que la primera se aprehende a través de una intuición, pero sensible, en tanto que a la segunda se alcanza por puro razonamiento analítico, es decir, por lo que cabe llamar una intuición intelectual, o si se prefiere, suprasensible. Pero por una vía o por otra, mediante la intuición noético-sensible o mediante la intuición analítico-suprasensible, es lo cierto que toda la teoría de la sustancia o de la realidad ha estado basada en dos afirmaciones: Primera, que se halla compuesta por notas o características que la hacen ser como es. Y segunda, que tenemos acceso intuitivo o, al menos, directo al conocimiento cierto, más aún, apodíctico de sus notas o características esenciales o últimas.

Así se ha entendido la "realidad" a lo largo de la mayor parte de la historia de la filosofía. Realidad es sustancia, y sustancia es conjunto de notas esenciales o constitutivas de una cosa, que la dotan de unidad y la 
diferencian de otras. De esa realidad tenemos conocimiento cierto y apodíctico, bien por vía intuitiva, bien por vía discursiva; es decir, por vía sensible o por vía suprasensible. La culminación de este modo de pensar es, sin duda, Leibniz.

En la exposición de la fenomenología de Husserl que Zubiri llevó a cabo el curso 1931-1932, una parte importante está dedicada a exponer la "intuición categorial", que para Husserl es el principio de los principios de todo conocimiento riguroso, ya "que toda intuición en que se da algo originariamente es un fundamento de derecho del conocimiento" (Husserl, 1962, p. 58). Para aclarar la intuición categorial fenomenológica, Zubiri tiene que situarla en el conjunto de las teorías de la intuición que se han dado en historia de la filosofía. Una de ellas es la de "intuición intelectual", a diferencia de la intuición sensible. En ella está, según Zubiri, el origen de toda la filosofía moderna. Y escribe: "Otro sentido más peligroso es el sentido que intuición intelectual ha tenido en la filosofía prekantiana y sobre todo en Leibniz. Intuición pura llama Kant al intelecto divino, recordando una afirmación de Descartes en virtud de la cual la intuición intelectual es un órgano distinto de la intuición sensible, cuya misión consiste en llegar a las cosas en sí mismas. La intuición intelectual ha sido el punto contra el cual más ha luchado Kant en su Crítica" (Zubiri, 2007, p. 568). Leibniz, como buen racionalista, es para Zubiri el modelo de pensador que intenta ver las cosas sub specie aeternitatis, desde el punto de vista de Dios, para quien no hay más que intuición, e intuición intelectual pura. En esa intuición se da la cosa entera; es la perfecta y completa comprensión de la mónada, que en última instancia es "un espejo de Dios" (Leibniz, 2003, p. 334).

\section{FRENTE A SUSTANCIALISMO E INTUICIONISMO, SUSTANTIVIDAD Y APREHENSIÓN PRIMORDIAL DE REALIDAD}

Leibniz es la versión más exagerada o extrema de la teoría de la sustancia defendida secularmente en filosofía. De ahí su importancia. Es un buen ejemplo de lo que el racionalismo inveterado de la filosofía ha entendido por realidad. La realidad es una mónada, y la mónada es la unidad de notas perfecta y autosuficiente en su propia línea. Por eso cada mónada es la representación de todo el universo en una perspectiva particular, la de la propia mónada de que se trate.

Mi impresión es que todos tendemos a entender los conceptos de "realidad" y de "cosa" de este modo, de forma más o menos leibniziana, y que eso dificulta, cuando no impide comprender el sentido de alguna de las tesis básicas de la filosofía de Zubiri, probablemente de su núcleo más importante. Porque ese núcleo está constituido, a mi modo de ver, por dos afirmaciones. Primera, que la realidad no es esencia ni sustancia que se aprehende por intuición, sea ésta sensible o intelectual, sino que la realidad es lo dado en la aprehensión sentiente en tanto que dado en ella. Y segunda, que eso dado no es nunca la esencia, sino lo que Zubiri llama "en propio" o "de suyo" o "sustantividad", que es la cosa aprehendida, pero no como "tal" cosa aprehendida (de ser esto así volveríamos de nuevo al intuicionismo), sino como simplemente "real". Esta diferencia es importante, porque si la aprehensión primordial aprehendiera el contenido en tanto que contenido, se trataría de una teoría intuicionista más, como tantas otras que se han dado a lo largo de la historia de la filosofía. El "de suyo" o "en propio" es la cosa, la cosa en sus notas, pero no en tanto que notas específicas o talitativas, sino en tanto que "reales". Esto es lo que obliga a Zubiri a distinguir entre "formalidad" y "contenido". En la aprehensión primordial se nos actualiza la cosa, y por tanto sus notas, pero no en tanto que contenido sino en tanto que formalmente reales. Sólo eso es "mera actualidad". El contenido no está "meramente actualizado". Si el contenido estuviera "meramente actualizado", nos hallaríamos de nuevo ante un intuicionismo, fuera del tipo que fuera. La aprehensión de las notas como reales, o dicho de otro modo, el carácter formalmente real de las notas y del sistema de notas, está dado en aprehensión primordial y tiene la contundencia de la verdad real, en tanto que la aprehensión del contenido de las notas en tanto que tal contenido, si se prefiere, el contenido del contenido, o el contenido como tal contenido, ni está meramente actualizado, ni hay verdad real de él. Lo contrario es entender a Zubiri desde categorías que no son las suyas, y que he tratado de representar paradigmáticamente en la obra de Leibniz.

A partir de aquí, tiene sentido que Zubiri rechazara el término "sustancia", y lo sustituyera por el de "sustantividad". La mónada es una sustancia, pero no cabe identificarla con lo que Zubiri llama "de suyo" o "en propio", a pesar de que a primera vista parecen cosas sinónimas. Ahí está el gran error, al que inducen expresiones ambiguas, como la que define la sustantividad como "conjunto clausurado y cíclico de notas", o como lo que "es independiente del medio y tiene control específico sobre él", o también como "suficiencia constitucional". Todas estas definiciones ponen en parangón formalidad y contenido, de tal 
modo que la aprehensión acaba identificándose con intuición (tanto de formalidad como de contenidos), lo que hace de la sustantividad otro tipo de sustancialidad o una teoría más sobre la sustancialidad de las cosas. No hay duda de que Sobre la esencia inclinaba a esta interpretación. Pero no creo que sea eso lo que dice la trilogía sobre la inteligencia. Si la sustancialidad primordialmente aprehendida se entiende no como "formalidad" sino también como "contenido", no hay modo de evitar su concepción como "mónada". Pero si, como Zubiri repite una y otra vez en la trilogía, realidad es pura formalidad de lo aprehendido en tanto que aprehendido, y a eso es precisamente a lo que llamamos sustantividad, hay que concluir que la sustantividad no es otra cosa que el "de suyo" o "en propio" de lo aprehendido en tanto que aprehendido. Personalmente creo que en la obra de Zubiri hay textos para defender ambas posturas, entre otras cosas porque, primero, él fue evolucionando claramente en este punto, y segundo, porque quizá nunca consiguió una coherencia perfecta en sus expresiones. Cabe plantearse, en cualquier caso, si no es la primera de esas interpretaciones la que intenta criticar cuando habla de la "logificación de la inteligencia". La elaboración del contenido en tanto que contenido no sería entonces propia de la aprehensión primordial de realidad sino del logos. Confundir aprehensión primordial y logos es logificar la inteligencia.

Vengo diciendo esto desde hace tiempo, que ha sido objeto de varias críticas. Por eso conviene aclararlo. Es evidente que en la aprehensión primordial está dada la "formalidad" de realidad, o la realidad en tanto que formalidad. La cuestión está en si se encuentra dado también el "contenido", y cómo. En este punto han ido configurándose dos interpretaciones. Para unos, los contenidos están dados en la aprehensión primordial en puridad de condiciones con la formalidad, y para otros no, de tal modo que como tales contenidos serían producto del logos.

Lo primero que es preciso decir es que los contenidos nunca pueden estar dados en paridad de condiciones con la formalidad, porque ésta se halla, dice Zubiri, "meramente actualizada", en tanto que los contenidos están actualizados, pero no "meramente". De no ser esto así, la realidad en tanto que dada en aprehensión primordial se definiría por su formalidad y su contenido (como sucede en Leibniz, aunque no haga explícita esta dicotomía), y no sólo por su formalidad, como sucede en Zubiri.

Pero si formalidad y contenido son parte de la aprehensión primordial, aunque de distinta manera, la cuestión está en saber cuál es esa manera. En el caso de la formalidad, la respuesta es clara: se trata de "mera actualización", donde "mera" significa que está actualizada y nada más, de tal modo que no hay nada ulterior que se añada a ella. Por el contrario, en el caso del contenido se trata de actualización pero no de "mera", lo que significa que aquí sí hay proceso ulterior, que ya no consistirá en "actualización" sino en "libre creación". (Zubiri, 1982, pp. 94ss)

El problema es qué debemos entender por "contenido", si es lo simplemente actualizado o si, por el contrario, el contenido aparece como tal más tarde, y por tanto es "libre creación". Zubiri no se plantea el tema explícitamente, pero sí dice que en la aprehensión primordial el contenido está como "este", pero no como "esto". (Zubiri, 1982, p. 96) La diferencia es fundamental. El contenido en tanto que "este" es su mera actualización como formalmente real, pero sin que aún, mediante un proceso completo que es obra del logos, se transforme en "esto", es decir, en contenido concreto o en contenido propiamente tal. En el "este" el contenido es inseparable de la formalidad; forman una unidad "compacta", dice Zubiri. Es el logos el que los separa y hace de las notas un contenido propiamente tal, es decir, un "esto" concreto. No hay contenido hasta que no se rompe la compacción, y esto es obra del logos.

La consecuencia de lo anterior es que el contenido, en tanto que tal contenido, no está dado en aprehensión primordial. Eso sería intuicionismo. En la aprehensión primordial están dadas, ciertamente, las notas, por ejemplo, el azul de este papel. Pero tal nota no está dada en tanto que azul sino en tanto que real. El azul es formalmente real. Eso es lo que está dado en aprehensión primordial. Eso es lo meramente actualizado. Ahora bien, ese momento del azul, el momento de formalidad, es inespecífico y trascendental, no específico y talitativo. Por tanto, lo que está dado en aprehensión primordial es el puro momento de formalidad del azul, no el momento de contenido del azul. Es más, Zubiri elaboró la teoría de la "aprehensión primordial de realidad" para esto. Conviene recordar que no hay "actos" de aprehensión primordial. Lo único que existe son actos de "aprehensión". Esos actos es obvio que tienen formalidad y contenido. Pero no lo tienen de igual modo. Para Zubiri, lo importante, lo fundamental del acto de aprehensión, es decir, lo que funda todo lo demás, es el momento de formalidad. Y para describirlo es para lo que elaboró la teoría de la aprehensión primordial. Pero no hay actos de aprehensión 
primordial salvo, quizá, en Dios. Hay actos de aprehensión. Para someter a análisis detallado el momento de formalidad, que es el fundante de todo lo demás, Zubiri introdujo la "aprehensión primordial". Es el momento primordial de la aprehensión, pero no se da nunca solo, sino siempre en el acto de aprehensión, en el que también hay, como es obvio, contenido. Pero el contenido, en tanto que contenido, no goza ya de las características propias de la formalidad. Lo otro sería, repito una vez más, intuicionismo. Lo que sea el azul en tanto que azul, su talidad o contenido, no me están dados en aprehensión primordial, y descubrirlo o elaborarlo será la penosa tarea del logos y de la razón. Y además será siempre una búsqueda inacabada e inacabable, porque ahora no se trata ya de "mera actualización" sino, como dice Zubiri, de "libre creación". Esta libre creación no afecta sólo al ficto, al concepto o al pensar racional, sino que afecta también al simple y mero percepto. Esto es lo que nos cuesta aceptar, y lo que distancia a Zubiri de cualquier tipo de intuicionismo.

Que el contenido consista en creación, no debería plantear mayores problemas. Más difícil es afirmar esa creación como "libre". Que la formación de conceptos sea libre, no resulta difícil de aceptar. Pero sí lo es el pensar que los perceptos, las percepciones, son creaciones libres. Parece claro que son creaciones, por lo ya dicho. Pero no se ve muy bien en qué puede consistir ahí el momento de libertad. Veo un objeto de color verde. Por supuesto que la percepción del verde es el resultado de todo un proceso educativo, en el que juega un papel fundamental el lenguaje, entre otras cosas. Pero no parece que sea resultado de un acto de libertad. $Y$ es que, a mi modo de ver, aquí "libre" no significa algo hecho con pleno conocimiento y voluntad decidida, es decir, de forma autónoma y completamente responsable. Libre tiene aquí el sentido de construcción que es de un modo pero podría haber sido de otro, y en el que hay, por ello mismo, un amplio grado de variabilidad o de libertad. En este sentido amplio del término, un acto espontáneo puede ser considerado también libre. $Y$ de esto es de lo que se trata. Los perceptos, las percepciones, son el resultado de complejos procesos en los que intervienen múltiples factores, unos biológicos e incluso genéticos, otros culturales, y otros individuales, generados por el propio sujeto mediante actos, bien espontáneos, bien deliberados.

Ahora estamos en condiciones de entender en sus justos términos el problema de la libre creación o la construcción de los contenidos, incluso en el caso más difícil, que es el de los perceptos. Debido a ello, no todos percibimos igual, y tampoco la percepción es idéntica en cada uno de nosotros a lo largo de nuestra vida. La actual neurobiología ha encontrado muchas pruebas de que esto es así. Y los literatos y artistas lo han plasmado de mil maneras distintas a lo largo de la historia. Abramos, como ejemplo, la novela escrita por Patrick Süskind y titulada El perfume. El niño JeanBaptiste Grenouille, expósito, recogido en el orfanato de madame Gaillard, en su soledad, aprendió a diferenciar todas las cosas por su olor:

A los seis años ya había captado por completo su entorno mediante el olfato. No había ningún objeto en casa de madame Gaillard, ningún lugar en el extremo norte de la Rue de Charonne, ninguna persona, ninguna piedra, ningún árbol, arbusto o empalizada, ningún rincón, por pequeño que fuese, que no conociera, reconociera y retuviera en su memoria olfativamente, con su identidad respectiva. Había reunido y tenía a su disposición diez mil, cien mil aromas específicos, todos con tanta claridad, que no sólo se acordaba de ellos cuando volvía a olerlos, sino que los olía realmente cuando los recordaba; y aún más, con su sola fantasía era capaz de combinarlos entre sí, creando nuevos olores que no existían en el mundo real (Süskind, 2010, pp. 36-37).

La descripción de Süskind muestra cómo la percepción está mediada por múltiples elementos, biológicos unos, culturales otros, y unos terceros personales. En el fondo, nadie percibe lo mismo. De ahí que percibir sea un fenómeno complejo y en alta medida creativo. No, la percepción de contenidos no puede identificarse con la aprehensión primordial de los olores como formalmente reales, que es lo único absoluto e invariante, lo básico, primario y persistente a todo lo largo del proceso intelectivo humano. Dadme un punto de apoyo y moveré la tierra, dijo Arquímedes. El punto de apoyo no es la intuición, como tradicionalmente se ha pensado, sino la mera formalidad de realidad. Es desde ahí desde donde construimos creativamente todos los contenidos.

Léase ahora el siguiente párrafo de Inteligencia y logos:

Una es la intelección de lo real en y por sí: es la aprehensión primordial. Otra, es la aprehensión de una cosa real 'entre' otras: es la aprehensión diferencial (esencialmente mediada). Planteada la cuestión en esta línea se ve ante todo que la aprehensión primordial es la forma suprema de inteligir, porque es la forma suprema de actualización de lo real en la 
intelección. Lo que sucede es que esta aprehensión es insuficiente diferencialmente: no nos hace inteligir lo que una cosa es en realidad, lo que es entre otras, es decir respecto de otras. La aprehensión diferencial nos da esta intelección pero es en la medida en que está inscrita en la aprehensión primordial. Y esta inscripción no concierne al contenido sino a la formalidad misma de realidad, la cual nos está dada en aprehensión primordial y sólo en ella. (Zubiri, 1982, p. 246)

¿Por qué dice Zubiri todo esto? ¿Qué es lo que le lleva a criticar el intuicionismo y a elaborar su teoría de la aprehensión primordial de realidad? A mi entender, los datos de la ciencia, principalmente los de la neurofisiología, la psicología y la lingüística. No se trata sólo de que las cosas no sean como nosotros las vemos, es decir, que no podamos atribuir a las cosas allende la aprehensión lo que se nos hace presente en la aprehensión. Por tanto, no se trata sólo de superar el realismo ingenuo. Es que una vez superado el realismo ingenuo, hay que ir todavía más allá, y decir que tampoco es verdad que las cosas sean, no ya allende la aprehensión, sino en nuestra aprehensión, tal como nos aparecen. Esto es lo que ahora está en juego. Es que la aprehensión humana es compleja, y resulta necesario distinguir en ella dos niveles, que es la razón por la que Zubiri se ve obligado a diferenciar la aprehensión primordial del logos. Cuando no se hace esa distinción y se considera que todo lo aprehendido es completamente verdadero en tanto que dado inmediatamente en la aprehensión, es decir, en tanto que intuido, se está cometiendo un grave error, aunque sólo fuera porque se hace de la aprehensión primordial un acto, cosa que no lo es. En la aprehensión, que es el único acto existente, hay mucho que no es inmediato sino mediato, porque lo hemos ido construyendo, consciente e inconscientemente, a través de mediaciones de todo tipo: lingüísticas, históricas, educacionales, etc. La aprehensión no es unitaria, sino que en ella hay que distinguir niveles; al menos, dos. $\mathrm{Y}$ ambos niveles son completamente distintos. Ambos son niveles de la aprehensión, y por tanto de lo dado, pero no de lo dado inmediatamente. La inmediatez de lo que Zubiri describe en el momento de aprehensión primordial, es total. Pero el momento del logos de lo aprehendido no se caracteriza por la inmediatez sino por las mediaciones. $Y$ a ese orden pertenecen todos los contenidos en tanto que contenidos, incluidos los perceptos.

Se me dirá que no todo contenido puede estar mediado, porque alguno habrá que sea primario. Por ejemplo, la ciencia nos ha descubierto muchas mediaciones de cosas que creíamos inmediatas, pero aun así tiene que partir de la inmediatez de lo aprehendido, por ejemplo, de esta luz verde que veo como verde. Por tanto, el contenido verde me estaría inmediatamente dado, y sin esa inmediatez ni la propia ciencia podría llevar a cabo su labor purificadora, ni elaborar la teoría de los colores. Pero aquí se desliza de nuevo un error. Lo que se quiere afirmar es que hay una especie de intuiciones básicas, por ejemplo, la intuición del verde, que es inmediata e indubitable, incluso para la ciencia. Pero esto es lo que Zubiri se niega a aceptar. No hay tal intuición del verde en tanto que verde. Hay actualización del verde en tanto que real, pero no en tanto que verde. Un ejemplo puede aclarar esto. Dos personas, una daltónica y otra que no lo es, van a cruzar una calle y se encuentran frente a un semáforo. Hay una luz que uno ve roja y otro verde. Los dos aprehenden esa luz como real, y por tanto entre ellos no existe ninguna diferencia en la actualización de la formalidad de realidad del verde. Si se les pregunta, ambos estarían convencidos de que están intuyendo el color, es decir, los dos ven lo mismo y coinciden, no sólo en el momento de formalidad sino también en el de contenido. Pero en este último punto se equivocan. Pueden coincidir en la formalidad y no en el contenido, a pesar de que en un principio tiendan a pensar lo contrario. El color verde no está meramente actualizado en tanto que color verde. EI color verde sólo es verde en relación al rojo, al azul, al blanco, etc. $Y$ eso requiere de un cierto proceso creativo. No lo demos vueltas, el verde en tanto que verde nunca está intuido, por más que nos lo parezca.

A esto se argüirá que en tal caso resultará imposible una teoría de la verdad. Lo cual pienso que tampoco es correcto. En primer lugar, porque hay una verdad de la formalidad de realidad, que es la que Zubiri llama verdad real. Y en segundo lugar, porque también hay una verdad del logos, por más que ya no tenga la contundencia de la verdad real. ¿Quién ha dicho que la verdad de los contenidos necesite ser absoluta? ¿Si ello fuera así, por qué hay que estar revisándolos continuamente? ¿Por qué los datos de la ciencia no son absolutos? Se dirá, apelando al Husserl de la Crisis, que precisamente porque los datos de la ciencia no son absolutos, tiene que haber algo previo a ellos que tenga carácter absoluto e indubitable. Y es verdad. La diferencia está en que él piensa que ese nivel indubitable tiene carácter "intuitivo", en tanto que en Zubiri esto no es así, y lo indubitable ha quedado reducido a la mera "formalidad de realidad." 


\section{LA POLÉMICA ENTRE EL SENSUALISMO Y EL RA- CIONALISMO: ¿HAY REALIDADES SÓLO SENTIDAS $Y$ REALIDADES SÓLO PENSADAS?}

Este es un punto absolutamente fundamental, en el que la confrontación entre Leibniz y Zubiri resulta particularmente fecunda. El problema es qué entendemos por realidad. Leibniz comienza ocupándose del mundo de los "posibles", que tienen, dice, "esencia", y que además tienden intrínsecamente a la existencia. Quiere esto decir que los posibles poseen algún tipo de realidad, por más que carezcan de existencia. Es obvio que esa realidad no es ni puede ser realidad "sentida", sino sólo realidad "pensada". La única realidad sentida es la de las "existencias". Y cuando Leibniz intenta describir éstas, tiene que exponernos su teoría de la "mónada", que es cualquier cosa menos empírica o perceptible. Y es que para Leibniz la verdadera realidad no se capta con los sentidos sino con la razón. La razón es el órgano de captación de la realidad.

Esto que le sucede a Leibniz es propio de todo el racionalismo. Cabe definirlo como la corriente que considera que hay realidades a las que el ser humano puede acceder por medio de la mera o pura razón. Lo mismo que hay verdades de razón, hay realidades de razón; es más, sólo la razón puede darnos la verdadera realidad de las cosas. Los sentidos son incapaces de hacer esto, de darnos la realidad. Esta es la línea gruesa de la historia de la filosofía, de Platón a Leibniz. "A lo largo de toda su historia, la filosofía ha atendido muy detenidamente a los actos de intelección (concebir, juzgar, etc.) en contraposición a los distintos datos reales que los sentidos nos suministran. Una cosa, se nos dice, es sentir, otra inteligir. Este enfoque del problema de la inteligencia contiene en el fondo una afirmación: inteligir es posterior a sentir, y esta posterioridad es una oposición. Fue la tesis inicial de la filosofía desde Parménides, que ha venido gravitando imperturbablemente, con mil variantes, sobre toda la filosofía europea" (Zubiri, 1980, pp. 11-12).

Zubiri no niega, como es obvio, que haya verdades de razón, e incluso que tales verdades de razón sean reales en tanto que tales verdades de razón (puesto que son productos de la libre creación de la inteligencia sentiente, elaborados en y desde la formalidad de realidad). Lo que niega es que el carácter real de su formalidad lleve a concluir que es también real el contenido, y por tanto la cosa misma. Esto es lo que se concluye, implícita o explícitamente, siempre que se ignora el momento formalmente sentiente de la intelección humana, y que por tanto se defiende la existencia en el ser humano de una inteligencia "pura" o de una razón "pura". De ese modo resulta innecesario distinguir formalidad de contenido, lo que lleva a extender la realidad a ambos dominios. Es lo típico del racionalismo en todas sus formas. No es que la inteligencia sentiente no pueda crear contenidos nuevos, irreales, como afirmaría en sensualismo estricto, es que ha de hacerlo necesariamente desde la formalidad de realidad, que es por definición no "pura" sino "sentiente". El contenido de lo irreal es irreal, pero dentro de la formalidad de realidad (Zubiri, 2005). "Lo sentiente de la razón no se refiere al contenido propio de ella, sino al carácter impresivo de esa realidad que la razón intelige de un modo peculiar marchando impresivamente en él; es impresión de realidad en marcha. Un número transfinito, un concepto abstracto, no son cualidades sentidas. Pero son inteligidas como algo real, y a fuer de tales se constituyen en la impresión de realidad en cuanto tal" (Zubiri, 1983, pp. 86-87). Los "posibles" de Leibniz no son, como él cree, obra de la "razón pura" sino de la "razón sentiente". Como las Ideas de Platón. La inteligencia es formalmente sentiente, por más que pueda elaborar, por libre creación, contenidos que no son ni pueden ser sensibles o sentidos. Es la diferencia entre razón sensible y razón sentiente (Zubiri, 1983, pp. 84-85). Las creaciones libres tendrán o no coherencia lógica, y por tanto verdad interna, pero tal verdad no será ni podrá ser la propia de la verdad real, como se pretende en el caso de las intuiciones, sino sólo la mera verdad dual o sólo la verdad racional. La formalidad es real, pero el contenido es irreal. Tal es lo que diferencia radicalmente a Zubiri de los distintos tipos de racionalismo. Estos, a través de la llamada "razón pura", creen posible extender la realidad de la formalidad al contenido, afirmando éste como real. En eso está la esencia del argumento ontológico, tan del gusto de Leibniz.

Zubiri piensa que no hay razón pura, sea la de Leibniz, la de Kant y la de todo el idealismo alemán. También la razón husserliana es un tipo de razón pura. La función de la epojé es, precisamente, purificar los contenidos de la razón de todo aquello que resulta contingente, es decir, impuro. $Y$ como en todos los racionalismos, también en él se produce el sutil paso del contenido ideal a la afirmación de su realidad. Del sentido de la realidad se pasa sin solución de continuidad a la realidad del sentido. Algo que ha hecho furor en la filosofía del siglo XX. De hecho, buena parte de la filosofía de la religión comienza preguntándose por el sentido de las cosas o de la vida, para desde ahí postular la realidad de Dios. Se trataría, a la postre, de una nueva versión del argumento ontológico. No es un azar que Zubiri no siga nunca ese camino. Es más, 
precisamente porque la razón zubiriana no es "pura" sino "sentiente", y el orden que nos actualiza la formalidad de realidad es lo que llamamos "mundo" (Zubiri, 1980, pp. 121ss), Dios no puede ser trascendente "al" mundo, como siempre postuló el racionalismo, sino trascendente "en" él. Las cosas del mundo tienen un contenido "talitativo" y una formalidad "trascendental". Pero además la realidad en tanto que realidad tiene "fundamento", que no es talitativo ni trascendental sino trascendente "en" el mundo. Es la realidad la que tiene un momento o una dimensión trascendente, y no sólo trascendental o talitativa. Para Zubiri, de lo "trascendente a" no podemos decir nada, debido a que la razón no es "pura" sino "sentiente". Esa presencia de lo trascendente en el mundo está ya dada en la aprehensión primordial bajo forma de "religación", que es puramente formal, y cuando el logos y la razón la dotan de contenidos pasa a convertirse en algo distinto, experiencia "religiosa".

De todo lo anterior se deduce que el fenómeno del poder de lo real y de la religación son universales, se dan en todo acto de aprehensión intelectiva, y que también es universal un cierto tipo de "religión", es decir, de experiencia del fundamento. Esa religiosidad será distinta según el "esbozo" que se construya sobre el fundamento, que a su vez dependerá del tipo de razón que se acepte. En el caso de la "razón pura", el esbozo postulará la existencia de una realidad trascendente al mundo, cuyos contenidos o caracteres se tomarán de las cosas del mundo, elevándolos al infinito por vía de eminencia. Es lo típico de lo que Heidegger llamó "ontoteología". En el caso de la "razón sentiente", el esbozo no podrá ser el de una realidad trascendente al mundo, porque de algo trascendente al mundo no cabe decir desde la inteligencia sentiente ni que sea realidad. Aquí el esbozo consistirá en preguntarse qué puede ser ese fundamento trascendente "en" la realidad del mundo. Eso que aquí llamamos fundamento, es lo que clásicamente se ha denominado Dios. No cabe aplicarle las categorías talitativas de las cosas del mundo, precisamente porque es trascendente en ellas, y porque caso de que se le aplicaran, caeríamos en el panteísmo. Como lo trascendente es el fundamento de la realidad trascendentalmente considerada, ha de consistir en una dimensión o nota de la realidad en tanto que realidad. Esa es la dimensión propiamente "religiosa". A dicho momento trascendente de la realidad en tanto que realidad Zubiri lo denomina constitutivo o causa, pero no eficiente sino "formal" de la realidad. "Dios está formalmente en las cosas como un constituyente formal suyo" (Zubiri, 2012, p. 465). Las cosas "sólo son reales siéndolo en Dios" (Zubiri, 2012, p. 466; cf. p. 166 y pp. 477-478). Como podrá advertirse, el camino de Zubiri en el clásico problema de Dios es radicalmente distinto al leibniziano.

\section{LA MÓNADA COMO SÍNTESIS DEL UNIVERSO, Y LA SUSTANTIVIDAD COMO RESPECTIVA AL MUNDO}

Hay, empero, algo en lo que los enfoques de Leibniz y Zubiri convergen y hasta coinciden. Se trata de la idea leibniziana de que la mónada es una síntesis de todo el universo, bien que en una perspectiva propia o desde un peculiar punto de vista. En Zubiri sucede algo similar. La sustantividad es el "de suyo" o "en propio" actualizado o presente en la aprehensión primordial en tanto que dado en ella. Esta es la definición "noológica" de sustantividad, la verdaderamente primaria en la obra de Zubiri. Pero en la aprehensión primordial, precisamente por su carácter formal e inespecífico, estamos en respectividad con toda la realidad en tanto que realidad. Al aprehender una cosa, aprehendemos, por tanto, la respectividad de la realidad mundana y del mundo entero. Es el fenómeno del "más" (Zubiri, 1980, pp. 115ss y p. 196). Es algo parejo a lo que dice Leibniz. El todo de la realidad se nos actualiza inmediatamente, a una, y por tanto la actualidad interna de la cosa, propia de su sustantividad y la actualidad de la cosa en la realidad del mundo, se dan de modo unitario e directo. "Sustantividad" y "actualidad" son conceptos correlativos, de tal modo que la sustantividad es la actualidad interna de las notas de una cosa, y el mundo es su actualidad externa. No es posible definir la sustantividad sino desde la actualidad interna. Y como la actualidad externa es congénere con la interna, resulta que tampoco es posible definir la sustantividad sin la actualidad externa o mundana. Eso explica que Zubiri diga a veces que en el fondo no hay más que una sustantividad, que es el cosmos entero. Dice del cosmos, no del mundo, pero también podría decirse esto último, habida cuenta de que el propio ser humano, que es el único absoluto distinto del cosmos, es absoluto, pero relativo. Lo único absolutamente absoluto para el ser humano es la realidad en tanto que realidad, es decir, el mundo. Aquí se ve claramente cómo la sustantividad necesita no sólo de la actualidad interna sino también de la externa.

Zubiri dice que la realidad humana es "absoluta", en el sentido de suelta de las demás talidades, si bien "relativamente"; es un "absoluto relativo". Conviene reparar en estos vocablos. "Absoluto" significa que trasciende todas las talidades del cosmos y se sitúa en el orden de la realidad en tanto que realidad. $Y$ "relativo", que la humana es una realidad cósmica, con 
una talidad dependiente de las demás. Esto último lo ha visto con toda claridad la ecología, a partir de la formulación por Ernest Haeckel de su principio básico, que el ser vivo no es tal sin su medio. Lo que sucede es que el ser humano, además de medio, Umwelt, tiene mundo, Welt. Por esto último es absoluto y por lo primero es relativo. Lo cual significa que la sustantividad humana sólo es tal en el interior de la sustantividad entera del cosmos, y que si es sustantiva debido a la actualidad interna de sus notas, es cósmica debido a la actualidad externa de sus notas, de modo que esta condición cósmica y por tanto esta actualidad externa le es constitutiva y esencial, o mejor, es sustantiva para él, porque forma parte ineludible de su realidad y de su sustantividad. En este nivel, el propiamente metafísico, la actualidad no sólo no es ulterior a la sustantividad, sino que es constituyente suya. Todo es actualidad, y la sustantividad es la actualidad interna de algo que aprehendemos en aprehensión primordial como "de suyo" o "en propio", bien que sólo parcial o relativamente. Sólo es de suyo o en propio "relativamente" a otros de suyos o en propios. En la aprehensión primordial el término básico es el de actualidad, de modo que la sustantividad noológica es la "actualidad interna" de las notas de un de suyo o en propio. Desde el punto de vista metafísico, esa actualidad interna no cobra todo su sentido más que integrada en la actualidad externa de la cosa en el cosmos y en el mundo, hasta el punto de que sólo hay una sustantividad "absoluta" quoad nos, que es la realidad sin más, el mundo. La realidad humana es una sustantividad más del mundo, y por eso no es absoluta, porque la actualidad externa al mundo no le es adventicia o colateral, sino intrínseca y constitutiva. Lo único sustantivo y absoluto, lo único sustantivamente absoluto, es el mundo, el orden de lo real en tanto que real.

Y aquí llegamos al punto más antileibniziano de la filosofía de Zubiri. Lo metafísicamente primario no es el orden de los "posibles" (las esencias posibles) sino el orden de la "actualidad". Los posibles son esencias. La actualidad no dice relación directa a la esencia sino a la realidad, o a la existencia, como decían los clásicos. Recuérdese la teoría escolástica del esse a diferencia de la essentia, el llamado actus essendi. Y es que desde el punto de vista metafísico, el problema es siempre el mismo, el problema del acto, o, para decirlo en términos leibnizianos, "por qué hay algo más bien que nada" (Leibniz, 2003, p. 685). Toda la metafísica ha girado siempre en torno a este misterio, que no porque se le den muchas vueltas resulta más claro. El misterio es el misterio. Ante él no cabe más que la actitud que ya formularon los griegos, el thaumázein, la admiración.

\section{CONCLUSIÓN: MONADOLOGÍA Y NOOLOGÍA}

El sistema de Leibniz es la metódica e implacable deducción de todas las consecuencias implícitas en el argumento ontológico. Un posible perfectísimo tiene que incluir entre sus notas la existencia. No todos los posibles pueden existir, porque todos son co-posibles, pero no co-existentes; por tanto, no todas las esencias pueden convertirse en existencias. De acuerdo con el argumento ontológico, sólo cobrarán existencia aquellas que sean más perfectas, porque ellas son los que tienen mayor aptitud para la existencia. Estas son las mónadas. Su existencia no es empírica, ni por tanto objeto de la clásicamente llamada intuición sensible, sino de una "intuición intelectual" que se da de modo pleno en Dios, y de las que los seres humanos participamos en alguna medida. Haciendo explícito todo este sistema, el ser humano remeda de algún modo la mente divina, colocándose, en tanto que ello le es posible, en el punto de vista de Dios. Si Dios es sabio, el ser humano, a través de todo este proceso, puede hacerse filósofo, es decir, "un pequeño dios" (Leibniz, 2003, p. 710; Leibniz, 2012, p. 199).

La tendencia natural de los seres humanos es a considerar que nuestra mente capta de modo adecuado la realidad de las cosas. Cuando la captación es inmediata y directa, hablamos de "intuición". Pocas filosofías han podido zafarse de este concepto. Las hay que han optado por la "intuición sensible", y otras por la "intuición intelectual" o suprasensible, como es el caso de Leibniz. En otros autores, como Husserl, el principio de todos los principios está en la llamada "intuición categorial". Pero siempre se trata de intuición. Y esto significa que la mente humana tiene acceso directo a la cosa con sus notas. Estas notas serán las notas percibidas, como en la intuición sensible; o las notas abstraídas, como en la intuición intelectual; o las notas inteligidas, como en la intuición leibniziana; o las notas puras, como en la intuición categorial. Pero siempre se trata de notas, de contenidos. $Y$ esto es lo que Zubiri considera incorrecto. Lo que se nos actualiza directamente no son las notas o los contenidos sino la formalidad de realidad, que consiste en "mera actualización". Se trata, como no podía ser de otro modo, de actualización de notas. No hay actualización sin notas. Pero es que el término nota significa dos cosas distintas. Nota es, en primer lugar, lo noto en tanto que real, y en segundo, lo noto en tanto que tal contenido (Zubiri, 1980, p. 33). Para Zubiri esta distinción es tan importante, que se vio obligado a establecer dentro de la "aprehensión", dos momentos, el de "aprehensión primordial" y el de "logos". La 
tendencia a ver la aprehensión primordial como un acto en sí, cosa a todas luces incorrecta, nos lleva a pensar que en la aprehensión primordial tienen que darse la forma y el contenido. Pero eso, dicho así, es incorrecto. El único acto es el de aprehensión, y en él, efectivamente, se dan de modo necesario formalidad y contenido. Si la aprehensión fuera intuitiva, si se nos diera todo en ella de modo inmediato, si todo en ella consistiera en mera actualización, no haría falta la dualización entre aprehensión primordial y logos, ni diferenciar la aprehensión primordial del percepto, o como Zubiri decía en etapas anteriores, la aprehensión simple de la simple aprehensión (Zubiri, 1985, p. 16 y p. 353; Zubiri, 1980, p. 67; Zubiri, 1982, p. 86). Pero no existe tal intuición. De hecho, Zubiri la rechaza (Zubiri, 1980, p. 67). Y la rechaza, porque el contenido no está dado en paridad de condiciones con la aprehensión primordial. La aprehensión primordial nos actualiza la realidad en tanto que realidad, la cosa en tanto que real, y por tanto en su dimensión transcendental. Por supuesto, nos actualiza también la cosa en su talidad, pero la talidad no está meramente actualizada, sino que necesita, para determinarse como tal talidad, es decir, como contenido concreto, de una elaboración ulterior que es obra del logos. Sólo él puede convertir el "este" en "esto", es decir, en "tal" contenido concreto.

¿Por qué cuesta tanto verlo así? A mi modo de ver, porque existe una tendencia natural a creer que nuestro conocimiento directo e inmediato es intuitivo. Sucede aquí lo mismo que con el realismo ingenuo. Superar la idea de que las cosas son en sí como nosotros las aprehendemos es una labor difícil y compleja, que a la humanidad le ha costado un esfuerzo de muchos siglos. Pues bien, pienso que hoy es preciso llevar a cabo una labor no menos cruenta, que es superar la creencia en que los contenidos de lo dado en la aprehensión tienen la misma contundencia que la aprehensión de la formalidad; dicho de otro modo, que la dimensión formal y trascendental de lo aprehendido se da en paridad de condiciones y características con la dimensión talitativa o de contenido. Si a lo primero se le denominó en la filosofía moderna "realismo ingenuo", a esto segundo es a lo que cabe llamar "subjetivismo ingenuo". Zubiri utiliza esta última expresión en su trilogía de la inteligencia (Zubiri, 1980, p. 178), y todos hemos pensado que la crítica iba dirigida contra el ciencismo y el psicologismo del siglo XIX, en la misma línea, por ejemplo, que la llevada a cabo por Husserl al comienzo de sus Investigaciones lógicas. Pero pudiera ser que esto no fuera así, y que en ese término no esté incluyendo sólo al ciencismo y al psicologismo, sino a la propia fenomenología, y en general a todo intuicionismo, sea del tipo que fuere. Aprehensión primordial no es lo mismo que intuición. Entre otras cosas, porque la intuición, al menos la sensible, lo es siempre de los contenidos inmediatamente percibidos. Y la percepción, para Zubiri, ni es inmediata ni es intuitiva.

De ser todo esto así, cabe concluir que la filosofía es un menester extraño, que lleva a poner en cuestión las creencias naturales, y por tanto a ver las cosas de un modo que, cuando menos, hay que considerar forzado, cuando no antinatural. Lo cual parece confirmar que los filósofos, en vez de caminar sobre los pies, andan siempre de cabeza.

\section{BIBLIOGRAFÍA}

Husserl, E. (1962). Ideas relativas a una fenomenología pura y una filosofía fenomenológica. México / Buenos Aires: Fondo de Cultura Económica.

Leibniz, G. W. (1992). Nuevos ensayos sobre el entendimiento humano. Madrid: Alianza.

Leibniz, G. W. (2003). Escritos filosóficos. Madrid: Antonio Machado.

Leibniz, G. W. (2012). Ensayos de Teodicea. Granada: Comares.

Marías J. (1960). Obras (vol. V). Madrid: Revista de Occidente.

Marías, J. (1998, 3 de diciembre). El joven Zubiri. $A B C$
Süskind, P. (2010). El perfume. Barcelona: Seix Barral.

Zubiri, X. (1980). Inteligencia sentiente: Inteligencia y realidad. Madrid: Alianza.

Zubiri, X. (1982). Inteligencia y logos. Madrid: Alianza.

Zubiri, X. (1983). Inteligencia y razón. Madrid: Alianza.

Zubiri, X. (1992). Sobre el sentimiento y la volición. Madrid: Alianza.

Zubiri, X. (1994). Los problemas fundamentales de la metafísica occidental. Madrid: Alianza

Zubiri, X. (1985). Sobre la esencia. Madrid: Alianza.
Zubiri, X. (2002). Sobre el problema de la filosofía y otros escritos (1932-1944). Madrid: Alianza.

Zubiri, X. (2005). El hombre: lo real y lo irreal. Madrid: Alianza.

Zubiri, X. (2007). Cursos universitarios (vol. 1). Madrid: Alianza.

Zubiri, X. (2010). Cursos universitarios (vol. 2). Madrid: Alianza.

Zubiri, X. (2012). El hombre y Dios: Nueva edición. Madrid: Alianza. 